TITLE:

\title{
Alternate stacking of transition metal ions and terephthalic acid molecules for the fabrication of self-assembled multilayers
}

\section{AUTHOR(S):}

SUGIMURA, Hiroyuki; YONEZAWA, Hiroyuki; ASAI, Shogo; SUN, Qing-Wei; ICHII, Takashi; LEE, KyungHwang; MURASE, Kuniaki; NODA, Kei; MATSUSHIGE, Kazumi

\section{CITATION:}

SUGIMURA, Hiroyuki ...[et al]. Alternate stacking of transition metal ions and terephthalic acid molecules for the fabrication of self-assembled multilayers. Colloids and Surfaces A: Physicochemical and Engineering Aspects 2008, 321(1-3): 249-253

\section{ISSUE DATE:}

2008-05-15

URL:

http://hdl.handle.net/2433/97893

\section{RIGHT:}

Copyright (c) 2008 Elsevier B.V.; This is not the published version. Please cite only the published version.; この論文は出版社版でありません。引 用の際には出版社版をご確認ご利用ください。 


\title{
Alternate Stacking of Transition Metal Ions and Terephthalic Acid Molecules for the
}

\section{Fabrication of Self-Assembled Multilayers}

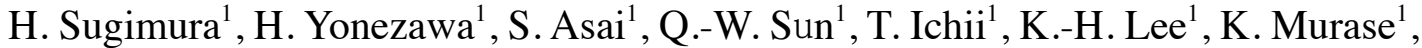 \\ K. Noda ${ }^{2}$, K. Matsushige ${ }^{2}$ \\ ${ }^{1}$ Department of Materials Science and Engineering, \\ Kyoto University, Sakyo, Kyoto 606-8501, Japan \\ ${ }^{2}$ Department of Electronic Science and Engineering, \\ Kyoto University, Nishikyo, Kyoto, 615-8540, Japan
}

\section{Corresponding author}

Hiroyuki Sugimura, Professor

Department of Materials Science and Engineering, Kyoto University

Sakyo, Kyoto 606-8501, Japan

TEL +81-75-753-9131

FAX +81-75-753-5484

E-mail hriyuki-sugimura@mtl.kyoto-u.ac.jp 


\section{Alternate Stacking of Transition Metal Ions and Terephthalic Acid Molecules for the Fabrication of Self-Assembled Multilayers}

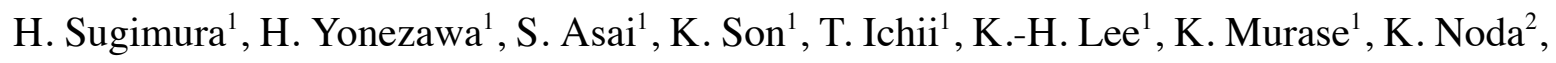
K. Matsushige ${ }^{2}$

${ }^{1}$ Department of Materials Science and Engineering, Kyoto University, Sakyo, Kyoto 6068501, Japan

${ }^{2}$ Department of Electronic Science and Engineering, Kyoto University, Nishikyo, Kyoto, 615-8540, Japan

Self-assembled multilayers consisting of transition metal ions and biscarboxyl acid molecules have been fabricated by a layer-by-layer chemisorption technique. As transition metal ion, $\mathrm{Zr}(\mathrm{IV})$ or $\mathrm{Ti}(\mathrm{IV})$ was employed, while terephthalic acid (TPA) was used as biscarboxyl molecule. In the multilayers, two TPA monolayers were bridged by one monolayer of $\mathrm{Zr}(\mathrm{IV})$ or Ti(IV) most likely through coordination bonds between the metal ions and the carboxyl groups in the TPA molecules. Although the both transition metal ions were successfully applied to construct multilayers, the multilayer structure of the Ti-TPA system was more disordered than that of the Zr-TPA system as revealed by grazing incidence $\mathrm{x}$-ray reflectivity.

Key words: Self-Assembled Monolayer; Self-Assembled Multilayer; Layer-by-Layer Stacking; Metal-Acid Coordination; Terephthalic Acid; Titanium; Zirconium 


\section{Introduction}

Self-assembly, that is, the spontaneous organization of organic molecules at a solid substrate surface during the chemisorption process, is a powerful means to fabricate organic monolayers as well as the Langmuir- Blodgett (LB) method. However, the self-assembling process has difficulty in fabricating multilayers which are readily fabricated by the LB method. There have been several reports describing processes for the fabrication of selfassembled multilayers on oxide substrates by the use of an organosilane self-assembled monolayer (SAM) as the bottom layer of the multilayer [1-10]. These reported methods are not simple but somewhat complicated, since an activation process-step of the bottom SAM surface via chemical or photochemical treatments is frequently needed before stacking an upper layer on it. Another approach to fabricate such supramolecular films on solid surfaces is the use of coordination chemistry [11]. For example, several types of multilayers have been fabricated through coordination bonds between metal ions with isocyanide or amino groups [12-15]. Mallouk and coworkers developed a promising method in which monolayers of alkyl-bisphosphonic acid and zirconium $(\mathrm{Zr})$ ions were alternately stacked [16]. Their method has proved to be quite useful to fabricate a variety of functional multilayers [17-25]. Besides phosphonic acid, carboxylic acid is expected to be promising in order to fabricate multilayers, since, as reported by Evans et al. [26], carboxylic acid molecules were self-assembled with $\mathrm{Cu}(\mathrm{II})$ ions. Furthermore, Aronoff et al. [27] reported that aliphatic acid molecules were immobilized on a $\mathrm{Zr}(\mathrm{IV})$-modified oxide surface and to form a robust SAM due to fairly strong coordinate bonds between $\mathrm{Zr}(\mathrm{IV}$ ) ions and carboxyl groups. Indeed, as similarly to the metal-phosphonic acid system, we have succeeded in fabricating a metal-carboxylic acid complex multilayer [28], although its self-assembled structure has not been elucidated in details yet.

Here we report on the fabrication process of metal-carboxylic acid complex 
multilayers in which terephthalic acid (TPA) is employed as a precursor for the organic layers. As the transition metal layers for the multilayers, $\mathrm{Zr}$ and titanium (Ti) are studied. Structures of the fabricated multilayers are characterized by grazing incidence X-ray reflectivity (GIXR) measurements and atomic force microscopy (AFM).

\section{Experimental}

Silicon ( $\mathrm{Si}$ ) substrates were cleaned by a photochemical method [29] as briefly described as follows. The substrate cut from a n-type $\mathrm{Si}(100)$ wafer were first sonicated in ethanol and ultra pure water in that order. Then the substrates irradiated in air for 20 min with vacuum ultraviolet (VUV) light at $172 \mathrm{~nm}$ in wavelength using a Xe excimer lamp as a light source. The atmospheric oxygen molecules were excited resulting in the formation of active oxygen species such as ozone and atomic oxygen. These active oxygen species oxidized and removed carboneous contamination remained on the substrate. In addition, a thin oxide layer less than 2-nm thick was grown on these cleaned substrates. Consequently, the substrate surfaces became hydrophilic so as to be most certainly terminated with hydroxyl groups. For AFM observation, Si substrates cut from an n-type Si(111) wafer were used. Prior to deposit a multilayer, the substrates were treated with the following processes. As similarly to the $\operatorname{Si}(100)$ substrates, the $\operatorname{Si}(111)$ substrates were sonicated in ethanol and water, in that order, and then cleaned by the VUV method. Next, the surface oxide layer on each of the substrate was removed etched in $5 \% \mathrm{HF}$ for $5 \mathrm{~min}$ at room temperature. Then, in order to expose a well-oriented and hydrogen-terminated (111) surface, the HF-etched substrates were treated in $40 \% \mathrm{NH}_{4} \mathrm{~F}$ solution for $30 \mathrm{sec}$ at $80{ }^{\circ} \mathrm{C}$. Finally, these substrates were photo-oxidized again by the VUV method with the identical conditions for the VUV-cleaning.

A prepared Si substrate was first immersed in a metal alcoxide solution or liquid for 10 min. When assembling a $\mathrm{Zr}$ layer, $\mathrm{Zr}(\mathrm{IV})$ tetra $n$-butoxide solution (80 wt.\% in 1-butanol, 
purchased form Sigma-Aldrich Co.) was used as received. In the case of Ti, titanium(IV) tetra n-butoxide (reagent grade, 97\%, purchased form Sigma-Aldrich Co.) liquid was used. This immersion process was conducted at room temperature in a low humidity atmosphere with a dew point below $-60{ }^{\circ} \mathrm{C}$. The substrate taken out were rinsed with 1-butanol, sonicated in 1butanol for 10 min and then dried with nitrogen gas flow. This series of the surface treating procedures is referred to as the $\mathrm{Zr}$-process or the Ti-process, respectively. Next, the substrates were immersed in a $3 \mathrm{mM}$ solution of terephthalic acid (TPA, 98\%, Sigma-Aldrich Co.) in $\mathrm{N}, \mathrm{N}$-dimethylformamide (DMF, 99.5\%, Nacalai Tesque, Inc.). The immersion was prolonged for $30 \mathrm{~min}$ in the atmosphere. The substrates were sonicated in DMF for $10 \mathrm{~min}$ and then blown dry. This series of the procedures is referred to as the TPA-process.

X-ray photoelectron spectra (XPS) were measured using an XPS system (Kratos Analytical Ltd., ESCA3400) with a Mg-K $\alpha$ X-ray source. Each XPS spectrum was calibrated so that a Si-Si peak from the Si substrate of a sample was referenced to $99.6 \mathrm{eV}$ in order to cancel binding energy shifts due to charge up effects. Grazing incidence X-ray reflectivity (GIXR) curves of the samples were measured using a X-ray reflectivity measuring instrument (Rigaku Co., ATX-G) with a $\mathrm{Cu}-\mathrm{K} \alpha$ X-ray source. Morphologies of the sample surfaces were acquired using an atomic force microscope (AFM, SII Nanotechnology Inc., SPI4000+SPA-300HV) in the intermittent contact mode with a $\mathrm{Si}$ cantilever (SII Nanotechnology, Si-DF20).

\section{Results and discussion}

As reported previously [28], a self-assembled multilayer consisting of $\mathrm{Zr}$ and TPA could be fabricated by simply repeating the $\mathrm{Zr}$ and TPA-processes. As schematically illustrated in Fig. 1(A), in this multilayer, two TPA monolayers were bridged with a $\mathrm{Zr}(\mathrm{IV})$ monolayer. The chemistry connecting these monolayers is most likely coordinate bonds 
between $\mathrm{Zr}(\mathrm{IV})$ ions and carboxyl groups. At the first step of the multilayer stacking, $\mathrm{Zr}(\mathrm{OBu})_{4}$ molecules are assembled onto a hydroxylated $\mathrm{SiO}_{2}$ surface resulting in the formation of $=\mathrm{Zr}(\mathrm{OBu})_{2}$ monolayer as illustrated in Fig. 1(B). On to this $\mathrm{Zr}$-modified surface, a TPA monolayer is formed through the coordination chemistry between $\mathrm{Zr}$ ions and carboxylic groups of the TPA molecules. Onto its carboxyl-terminated surface, one $\mathrm{Zr}$ monolayer is again self-assembled. Consequently, a $\mathrm{Zr}$-TPA self-assembled multilayer is successfully fabricated. Figures 2(A) and 2(B) show $\mathrm{Zr} 3 \mathrm{~d}$ and $\mathrm{C}$ 1s XPS profiles, respectively, obtained from the sample fabricated by 6 pairs of the $\mathrm{Zr}$ and TPA-processes. The $\mathrm{Zr} 3 \mathrm{~d}$ spectrum clearly indicates that the deposited film certainly contains $\mathrm{Zr}$ and its chemical state is $\mathrm{Zr}(\mathrm{IV})$. The $\mathrm{C}$ 1s spectrum has one main peak at around $286 \mathrm{eV}$ and a small side peak at around $290 \mathrm{eV}$. The main peak corresponds mainly to aromatic carbon atoms originated form the TPA molecules assembled into the Zr-TPA multilayer sample. The side peak corresponds to carboxyl groups coordinated to $\mathrm{Zr}(\mathrm{IV})$ ions. We have examined $\mathrm{Ti}$ as an alternative of the $\mathrm{Zr}$ center for the multilayer stacking. Figures 2(C) and 2(D) show Ti 2p and C 1s XPS profiles, respectively, obtained from a sample fabricated by two Ti-process and one TPA-process. Namely, the sample consists of triple layers, that is, one TPA monolayer sandwiched two Ti monolayers (Ti-TPA-Ti). The Ti $2 \mathrm{p}$ spectrum clearly demonstrates that $\mathrm{Ti}$ is certainly incorporated in the grown film and its chemical state is $\mathrm{Ti}$ (IV) ions. $\mathrm{Ti}(\mathrm{IV})(\mathrm{OBu})_{4}$ is demonstrated to be applicable to the multilayer stacking as well as $\mathrm{Zr}(\mathrm{IV})(\mathrm{OBu})_{4}$. The $\mathrm{C}$ 1s spectrum has two distinct peaks as similarly to Fig. 2(B). However, positions of these peaks are shifted toward the lower energy direction compared with the $\mathrm{C} 1 \mathrm{~s}$ spectrum of the Zr-TPA sample. Its reason is discussed as follows. As illustrated in Fig. 1, butoxide groups are considered to remain on the top surface of the Ti-TPA-Ti triple-layer. Hence, the main peak originates with photoelectrons from aromatic carbons in the TPA molecules and alkyl carbons in the surface butoxide groups. Similarly, the side peak 
corresponds to photoelectrons from $\underline{\mathrm{C}}-\mathrm{O}$ in the surface butoxide layer in addition to carboxyl groups coordinated to Ti(IV) ions.

Multilayered structures of Zr-TPA and Ti-TPA samples have been studied as shown in Figs. 3(A) and 3(B) in which X-ray reflectances of the samples are plotted as a function of grazing incident angle of X-ray. Both these reflectance curves show a wavy pattern indicating that a certain multilayered structure is present in each of the deposited films. Based on fitting models as schematically illustrated in the graphs, X-ray reflectance curves have been calculated and are indicated as solid curves in the graphs. Each fitting model consists of a Si substrate, an oxide layer on the substrate and five pairs of metal-TPA bilayer. When calculating the fitting curves, one metal-TPA bilayer was not treated as consisting of two layers but was assumed to be a uniform single layer. Each interface was assumed to have a sub-nm roughness as expected from AFM imaging of the samples and substrate surfaces. These calculated curves are in good accordance with the experimental results. Hence it can be conclude that the films consist of five pairs of metal-TPA bilayers as we have expected. Close inspection of the reflectance curves shows that the reflectance wave amplitude of the Ti-TPA multilayer sample is smaller than that of the Zr-TPA multilayer sample. This is primary because a smaller cross section of Ti in X-ray scattering due to its lower atomic weight than Zr. Besides this, the accordance degree between the experimental result and the calculated curve for the Ti-TPA multilayer sample is worse than the Zr-TPA multilayer sample. This implies that the Ti-TPA multilayer might be more disordered than the Zr-TPA multilayer.

The layer-stacking behavior of the Ti-TPA multilayer was thus studied in further details as shown in AFM images of Fig. 4. Figure 4(A) indicated an AFM image of an oxide covered $\mathrm{Si}$ substrate. Through the etching in 5\% $\mathrm{HF}$ and $40 \% \mathrm{NH}_{4} \mathrm{~F}$, a $\mathrm{Si}(111)$ substrate surface becomes to consist of atomically flat terraces separated with a monoatomic step. On this "step \& terrace" surface, a Si oxide layer was grown by the VUV oxidation method with 
preserving the "step \& terrace" structure of the Si surface as demonstrated in Fig. 4(A). Onto this "step \& terrace" oxide surface, a Ti-TPA multilayer was deposited. When deposited with a single Ti layer, a bilayer of Ti/TPA and a triple layer of Ti/TPA/Ti, "step \& terrace" structure of the substrate remain on the sample surfaces. However, it becomes distorted when deposited with two pairs of Ti/TPA bilayer. When deposited with a five-layered film, that is, $\mathrm{Ti} /(\mathrm{TPA} / \mathrm{Ti})_{2}$, there is no "step \& terrace" feature on the sample surface indicating that the disordering of molecular arrangement and orientation becomes apparent.

Chemical compositions of the multilayer samples as estimated by XPS were summarized in Table 1. There are large signals of $\mathrm{Si}$ and $\mathrm{O}$ from the oxide-covered $\mathrm{Si}$ substrate in each sample. With increasing the stacked layer number, concentrations of $\mathrm{O}, \mathrm{C}$, $\mathrm{Zr}$ and $\mathrm{Ti}$ increase since these components are included in the Zr-TPA and Ti-TPA systems. The ratios of the single pair samples, that is, 7.8 and 10.1. Since one TPA molecule has 8 carbon atoms and two TPA molecules are thought to be assembled with one metal atom as schematically illustrated in Fig. 1, the stoichiometric $\mathrm{C} / \mathrm{Zr}$ and $\mathrm{C} / \mathrm{Ti}$ values are 16 . This means that a number of self-assembled TPA molecules is smaller than that of the stoichiometric value in each multilayer or the stacked $\mathrm{Zr}$ or Ti layers are not a single layer. In addition, the $\mathrm{C} / \mathrm{Zr}$ and $\mathrm{C} / \mathrm{Ti}$ ratios decrease with the stacked layer number, indicating that the number of TPA molecules in an upper layer is smaller than that of the lower layer. These results are consistent with the results described in the previous paragraph that the multilayer structure becomes disordered with repeating layer stacking.

\section{Conclusion}

We have fabricated self-assembled multilayers consisting of aromatic biscarboxylate, i.e., TPA, monolayers, and transition metal, i.e., $\mathrm{Zr}(\mathrm{IV})$ or $\mathrm{Ti}(\mathrm{IV})$, monolayers by means of the layer-by-layer chemisorption method. In these multilayers, two TPA monolayers were bridged 
by one monolayer of $\mathrm{Zr}(\mathrm{IV})$ or $\mathrm{Ti}(\mathrm{IV})$ most likely through coordination bonds between the metal ions and the carboxyl groups in the TPA molecules. Although the both transition metal ions were found to be applicable to construct multilayers, the multilayer structure of the TiTPA system was more disordered than that of the Zr-TPA system as revealed by GIXR. The carboxyl-metal multilayer system demonstrated here, however, is expected to be promising for the nanoscopic surface architecture in order to design and construct novel functions using a wide variety of organic biscarboxyl molecules applicable to the system.

\section{References}

[1] L. Netzer, R. Iscovici, J. Sagiv, Thin Solid Films 99 (1983) 235.

[2] N. Tillman, A. Ulman, J. F. Elman, Langmuir 5 (1989) 1020.

[3] W. Lin, W. Lin, G. K. Wong, T. J. Marks J. Am. Chem. Soc. 118 (1996) 8034.

[4] T. Takahagi, Y. Nagasawa, A. Ishitani, Jpn. J. Appl. Phys. 35 (1996) 3542.

[5] S. Heid, F. Effenberger, Langmuir 12 (1996) 2118.

[6] S. Katom C. Pac, Langmuir 14 (1998) 2372.

[7] J. Naciri, J. Y. Fang, M. Moore, D. Shenoy, C. S. Dulcey, and R. Shashidhar, Chem. Mater. $12(2000) 3288$.

[8] Mong-Tung Lee and Gregory S. Ferguson, Langmuir 17 (2001) 762.

[9] T. Lummerstorfer and H. Hoffmann, J. Phys. Chem. B 108 (2004) 3963.

[10] H. Sugimura, L. Hong and K.-H. Lee, Jpn. J. Appl. Phys. 44 (2005) 5185.

[11] M. Haga, and T. Yutaka, Trends in Molecular Electrochemistry, A. J. L. Pombeiro and C. Amatore Eds., Marcel Dekker, (2004) 311.

[12] M. Maskus and H. D. Abruña, Langmuir 1996, 12, 4455.

[13] M. A. Ansell, E. B. Cogan, and C. J. Page, Langmuir 2000, 16, 1172.

[14] M. Altman, A. D. Shukla, T. Zubkov, G. Evmenenko, P. Dutta, and M. E. van der 
Boom, J. Am. Chem. Soc. 2006, 128, 7374.

[15] M. Wanunu, S. Livne, A. Vaskevich, and I. Rubinstein, Langmuir 2006, 22, 2130.

[16] H. Lee, L. J. Kepley, H.-G. Hong, T. E. Mallouk， J. Am. Chem. Soc. 110 (1988) 618.

[17] S. Akhter, H. Lee, H.-G. Hong, T. E. Mallouk, J. M. White, J. Vac. Sci. Technol. A 7 (1989) 1608

[18] H. E. Katz, M. L. Schilling, C. E. D. Chidsey, T. M. Putvinski, R. S. Hutton, Chem. Mater. 3 (1991) 699.

[19] H. C. Yang, K. Aoki, H.-G. Hong, D. D. Sackett, M. F. Arendt, S.- L. Yau, C. M. Bell, T. E. Mallouk, J. Am. Chem. Soc. 115 (1993) 11855.

[20] X.-H. Xu, H. C. Yang, T. E. Mallouk, A. J. Bard, J. Am. Chem. Soc. 116 (1994) 8386.

[21] S. B. Bakiamoh , G. J. Blanchard, Langmuir 15 (1999) 6379.

[22] G. A. Neff, M. R. Helfrich, M. C. Clifton, C. J. Page, Chem. Mater. 12 (2000) 2363.

[23] A. Hatzor, T. Moav, S. Yoshelis, A. Vaskevich, A. Shanzer, I. Rubinstein, Langmuir 16 (2000) 4420

[24] A. Shida, H. Sugimura, M. Futsuhara, O. Takai, Surf. Coat. Technol. 169-170 (2003) 686.

[25] J. A. Libera, R. W. Gurney, S. T. Nguyen, J. T. Hupp, C. Liu, R. Conley, M. J. Bedzyk, Langmuir 20 (2004) 8022.

[26] S. D. Evans, A. Ulman, K. E. Goppert-Berarducci, L. J. Gerense, J. Am. Chem. Soc. $1991,113,2130$

[27] Y. G. Aronoff, B. Chen, G. Lu, C. Seto, J. Schwartz and S. L. Bernasek, J. Am. Chem. Soc. 119 (1997) 259.

[28] H. Yonezawa, K.-H. Lee, K. Murase, H. Sugimura, Chem Lett. 35 (2006) 1392.

[29] H. Sugimura, A. Hozumi, T. Kameyama, O. Takai, Surf. Interf. Anal. 2002, 34, 550. 
Figure \& Table captions

Fig. 1. Growth of self-assembled multilayer. (A) Multilayer consisting of altanately stacked transition metal and terephthalic acid (TPA) monolayers. (B) Modification of a hydroxylated $\mathrm{Si}$ oxide surace with metal tetra n-butoxide, $\mathrm{M}(\mathrm{OBu}) 4$. (C) Multilayer stacking chemistry.

Fig. 2. X-ray photoelectron spectra of the Zr-TPA and Ti-TPA samples. (A) Zr 3d and (B) C 1s spectra of the (TPA/Zr) $)_{6}$ film. (C) Ti 2p and (D) C 1s spectra of the Ti/TPA/Ti film.

Fig. 3. GIXR profiles. (A) 6 pairs of TPA/Zr on $\mathrm{SiO}_{2} / \mathrm{Si}$. (B) 6 pairs of TPA/Ti on $\mathrm{SiO}_{2} / \mathrm{Si}$.

Fig. 4. Chenges in surface morphology during the TPA/Ti mulitilayer gorwth. (A) Oxidecovered $\mathrm{Si}$ substrate $\left(\mathrm{SiO}_{2} / \mathrm{Si}\right)$. (B) $\mathrm{SiO}_{2} / \mathrm{Si}$ substrate modified with $\mathrm{Ti}(\mathrm{OBu}) 4$, (C) a pair of TPA/Ti film (TPA/Ti-SiO $/ 2 / \mathrm{Si}$ ), (D) Ti/TPA/Ti film on $\mathrm{SiO}_{2} / \mathrm{Si}$, (E) two pair s of TPA/Ti film (TPA/Ti $)_{2}$ film ((TPA/Ti) $\left.)_{2}-\mathrm{SiO}_{2} / \mathrm{Si}\right)$ and $(\mathrm{F}) \mathrm{Ti} /(\mathrm{TPA} / \mathrm{Ti})_{2}$ film on $\mathrm{SiO}_{2} / \mathrm{Si}$.

Table 1. Atomic concentraion (\%) and C/metal ratios from XPS measurements of the Zr-TPA and Ti-TPA multilayers. 


\section{Figure $1 \mathrm{H}$. Sugimura et al.}

(A)

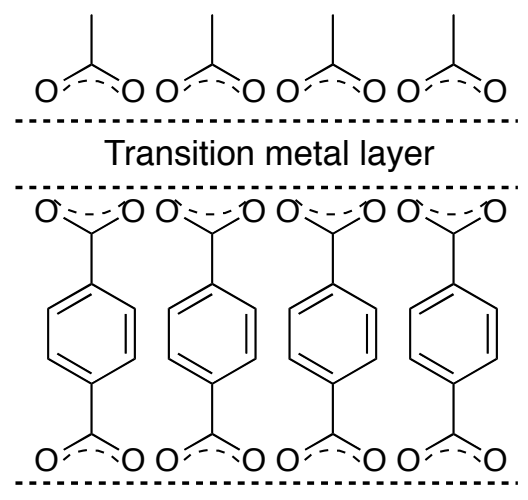

Transition metal layer

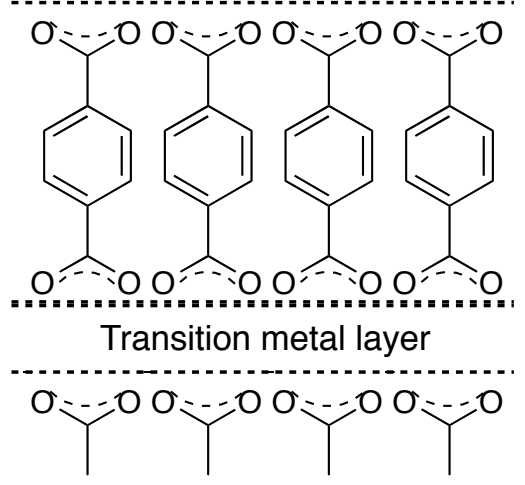

(B)

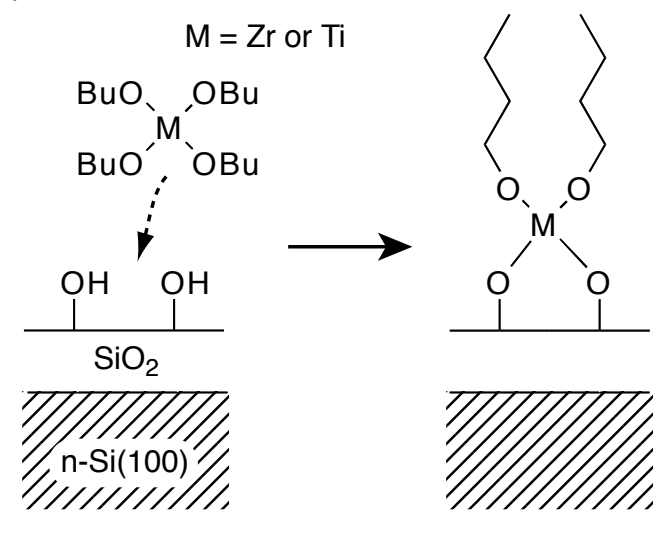

(C)

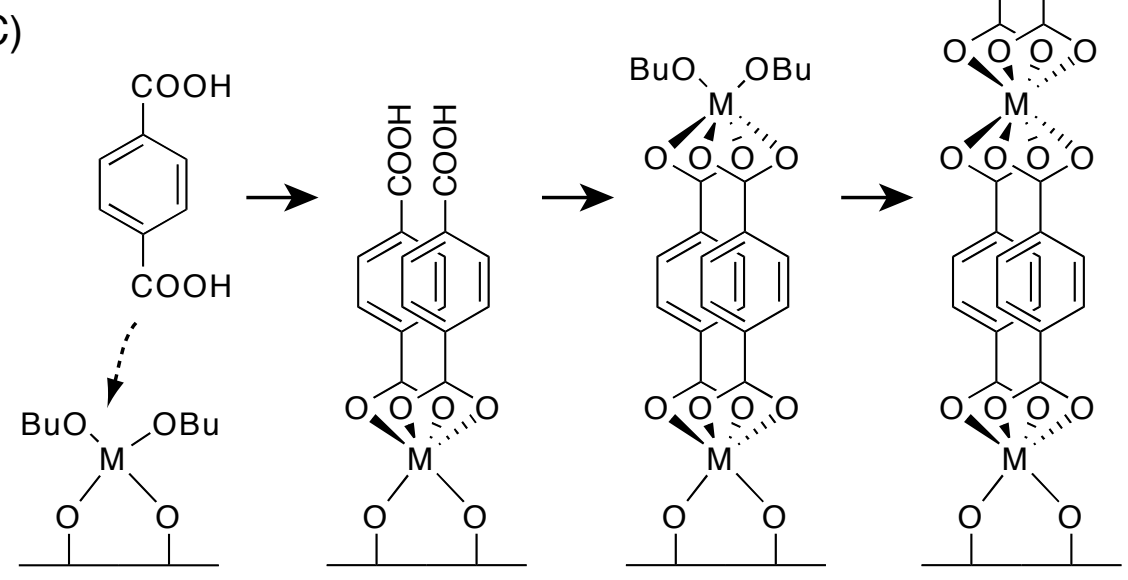

Fig. 1. Growth of self-assembled multilayer. (A) Multilayer consisting of altanately stacked transition metal and telephtalic acid (TPA) monolayers. (B) Modification of a hydroxylated Si oxide surace with metal tetra n-butoxide, $\mathrm{M}(\mathrm{OBu}) 4$. $(\mathrm{C})$ Multilayer stacking chemistry. 


\section{Figure $2 \mathrm{H}$. Sugimura et al.}

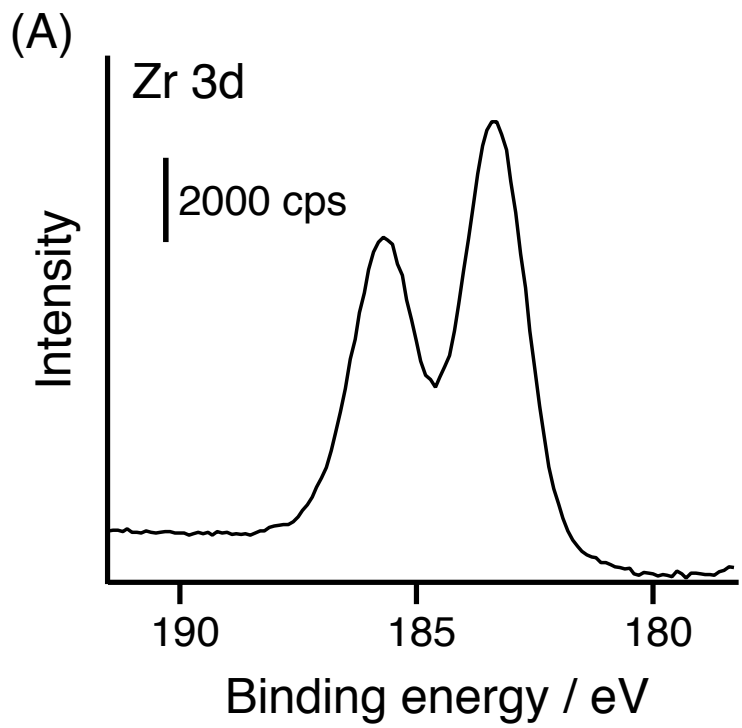

(C)

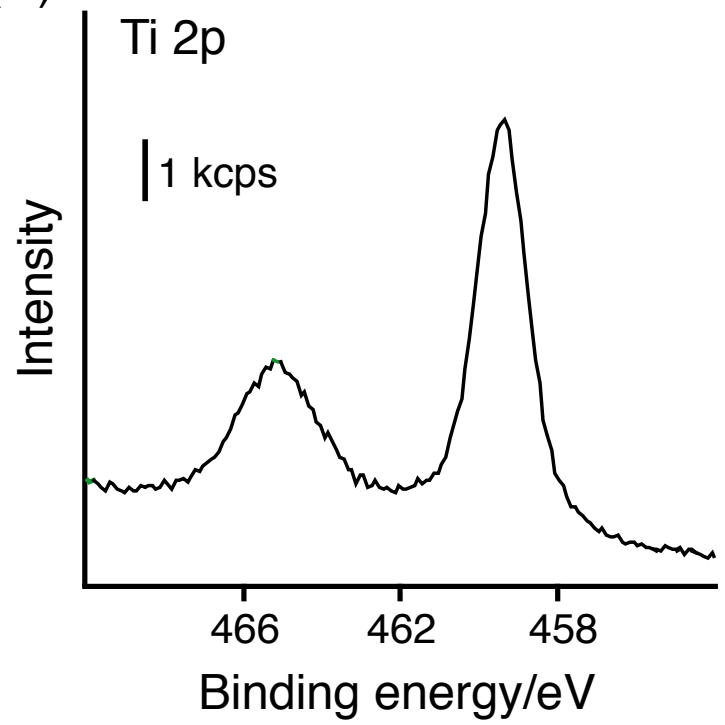

(B)

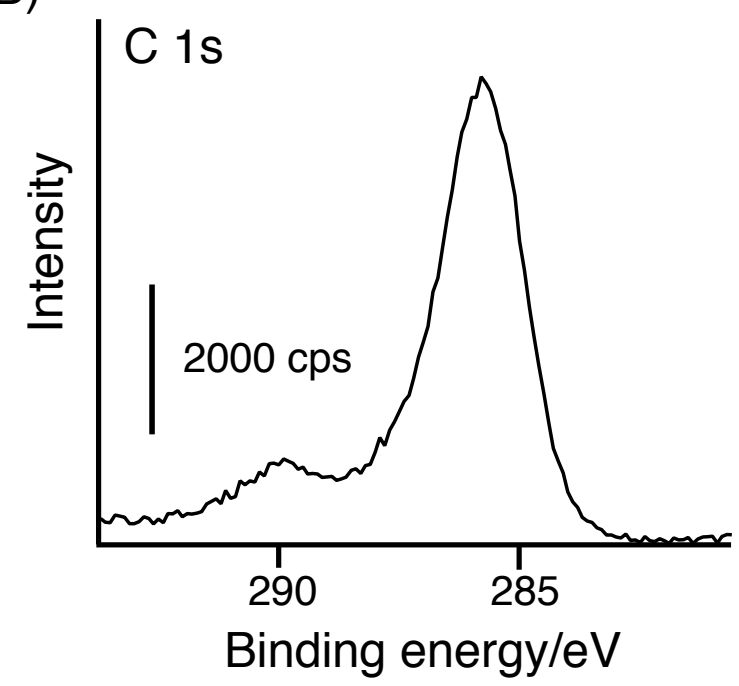

(D)

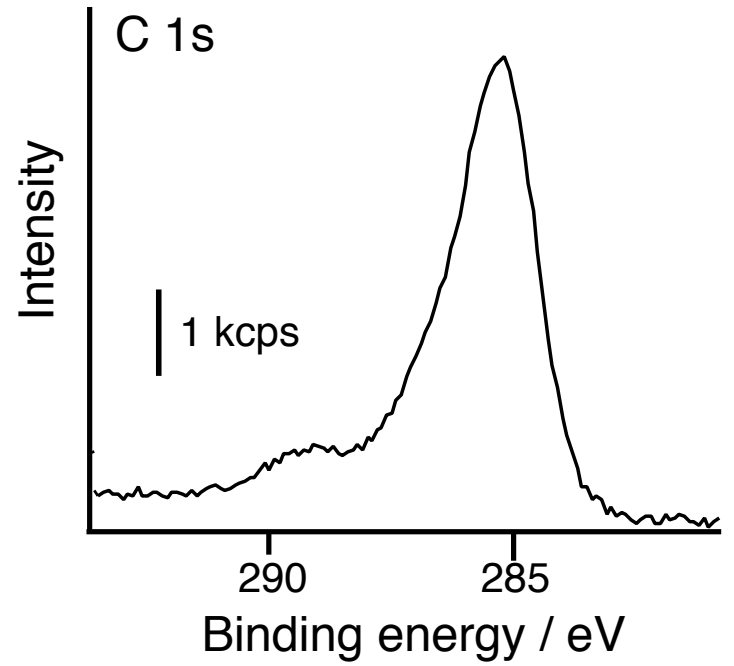

Fig. 2. X-ray photoelectron spectra of the Zr-TPA and Ti-TPA samples. (A) $\mathrm{Zr} 3 \mathrm{~d}$ and (B) C 1s spectra of the (TPA/Zr)6 film. (C) Ti 2p and (D) C 1s spectra of the Ti/TPA/Ti film. 


\section{Figure $3 \mathrm{H}$. Sugimura et al.}

(A)

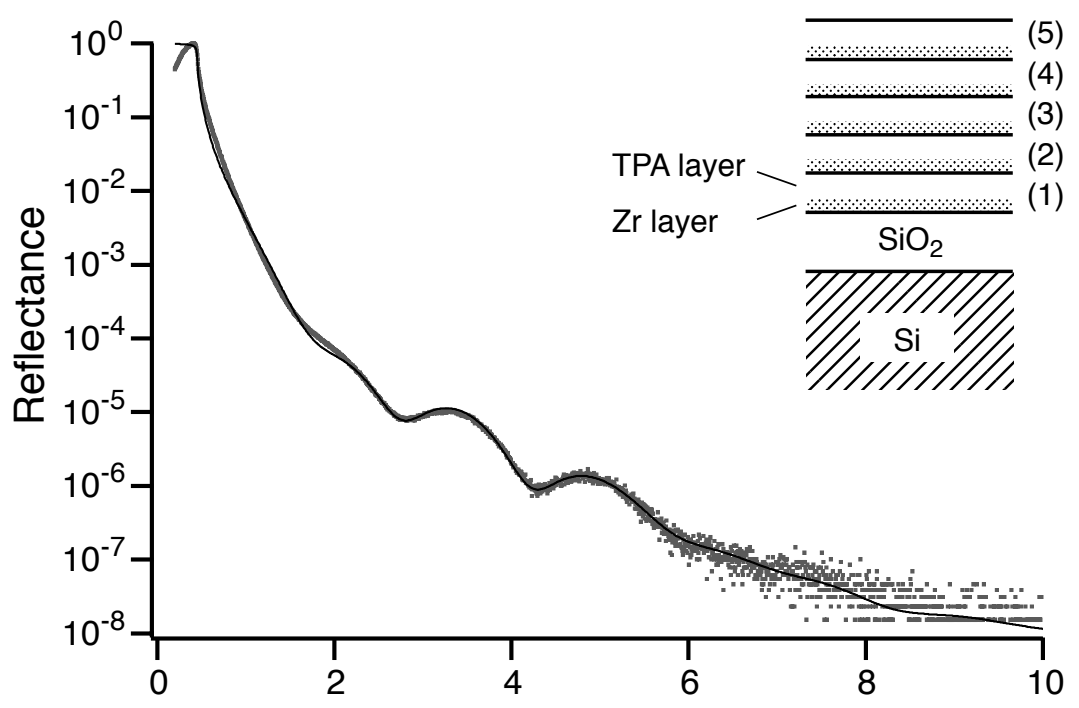

$2 \theta$ / deg.

(B)

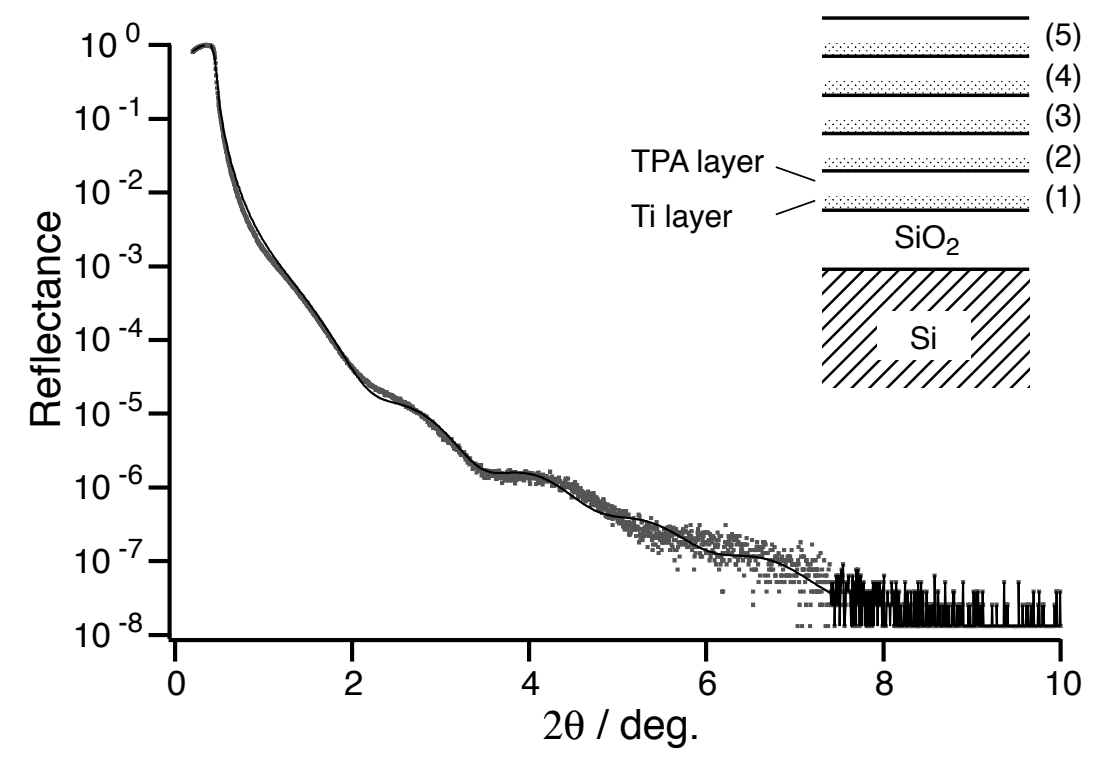

Fig. 3. GIXR profiles. (A) 5 pairs of TPA/Zr on $\mathrm{SiO}_{2} / \mathrm{Si}$. (B) 5 pairs of $\mathrm{TPA} / \mathrm{Ti}$ on $\mathrm{SiO}_{2} / \mathrm{Si}$. 


\section{Figure $4 \mathrm{H}$. Sugimura et al.}

(A) $\mathrm{SiO}_{2} / \mathrm{Si}$

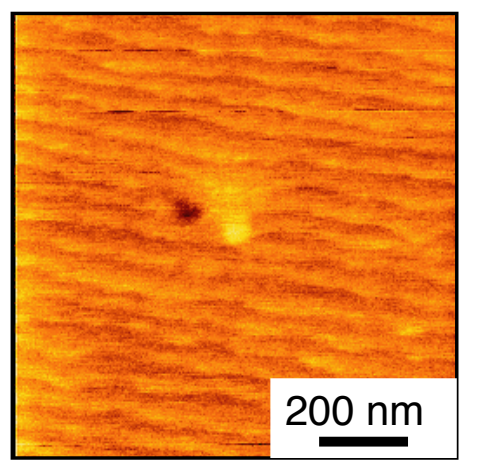

(D) Ti/TPA/Ti-SiO $2 / \mathrm{Si}$

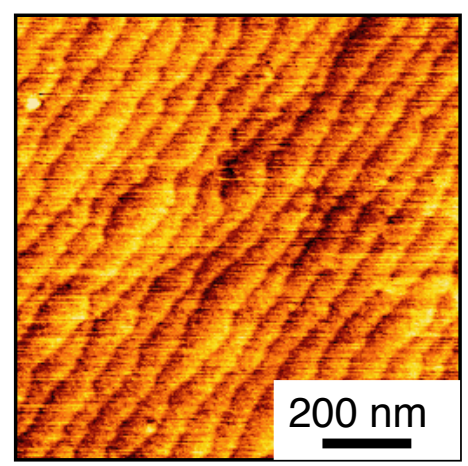

(B) $\mathrm{Ti}_{-} \mathrm{SiO}_{2} / \mathrm{Si}$
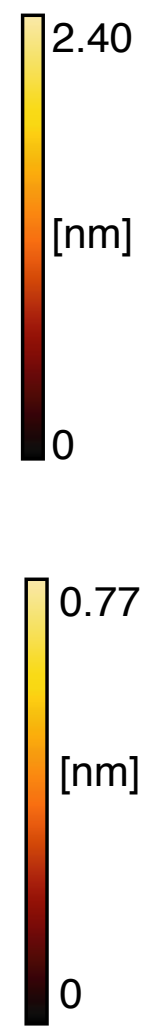

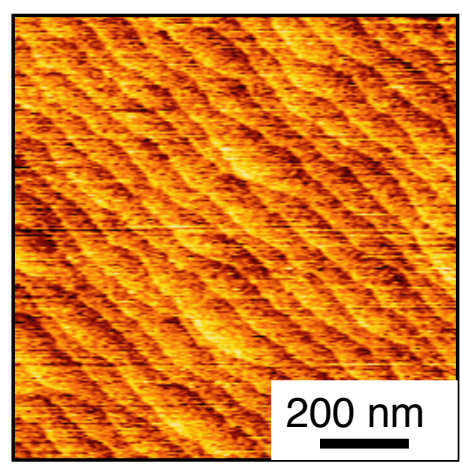

(E) $(\mathrm{TPA} / \mathrm{Ti})_{2}-\mathrm{SiO}_{2} / \mathrm{Si}$

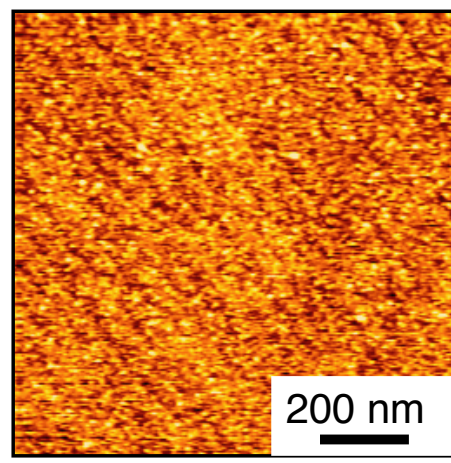

(C) $\mathrm{TPA} / \mathrm{Ti}-\mathrm{SiO}_{2} / \mathrm{Si}$

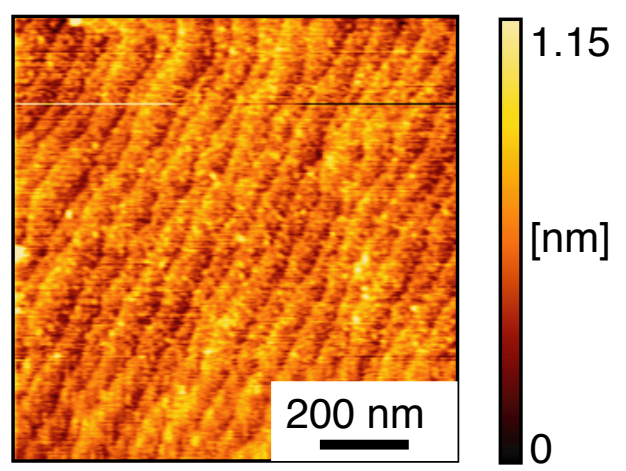

(F) $\mathrm{Ti} /(\mathrm{TPA} / \mathrm{Ti})_{2}-\mathrm{SiO}_{2} / \mathrm{Si}$

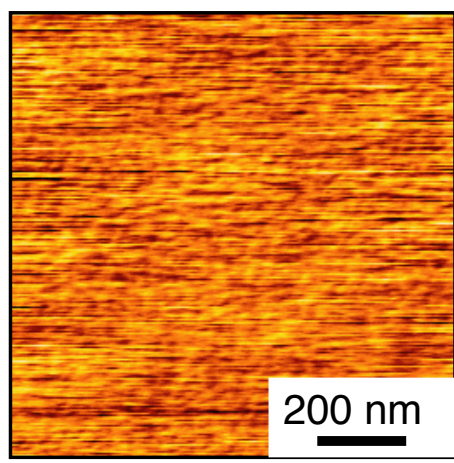

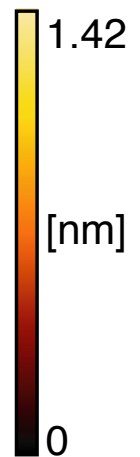

Fig. 4. Chenges in surface morphology during the TPA/Ti mulitilayer gorwth. (A) Oxide-covered $\mathrm{Si}$ substrate $\left(\mathrm{SiO}_{2} / \mathrm{Si}\right)$. (B) $\mathrm{SiO}_{2} / \mathrm{Si}$ substrate modified with $\mathrm{Ti}(\mathrm{OBu}$ 4, (C) a pair of TPA/Ti film (TPA/Ti-SiO2/Si), (D) Ti/TPA/Ti film on $\mathrm{SiO}_{2} / \mathrm{Si}$, (E) two pair s of TPA/Ti film (TPA/Ti)2 film ((TPA/Ti)2-SiO2/Si) and (F) $\mathrm{Ti} /(\mathrm{TPA} / \mathrm{Ti}) 2$ film on $\mathrm{SiO} 2 / \mathrm{Si}$. 
Table 1 Atomic concentraion (\%) and C/metal ratios from XPS measurements of the Zr-TPA and Ti-TPA multilayers.

\begin{tabular}{lccccc|cc}
\hline Multilayer & $\mathrm{Si}$ & $\mathrm{O}$ & $\mathrm{C}$ & $\mathrm{Zr}$ & $\mathrm{Ti}$ & $\mathrm{C} / \mathrm{Zr}$ & $\mathrm{C} / \mathrm{Ti}$ \\
\hline$(\mathrm{Zr}-\mathrm{TPA})_{1}$ & 49.7 & 38.2 & 10.7 & 1.4 & - & 7.8 & \\
\hline${\text { Zr-TPA })_{2}}$ & 48.4 & 38.3 & 11.1 & 2.2 & - & 4.9 & \\
\hline$(\mathrm{Zr}-\mathrm{TPA})_{4}$ & 34.3 & 41.1 & 19.0 & 5.7 & - & 3.4 & \\
\hline$(\mathrm{Ti}-\mathrm{TPA})_{1}$ & 38.0 & 39.6 & 20.4 & - & 2.0 & - & 10.1 \\
\hline$(\text { Ti-TPA })_{2}$ & 33.4 & 39.1 & 24.8 & - & 2.7 & - & 9.1 \\
\hline$(\text { Ti-TPA })_{4}$ & 31.7 & 41.4 & 22.9 & - & 4.0 & - & 5.8 \\
\hline
\end{tabular}

